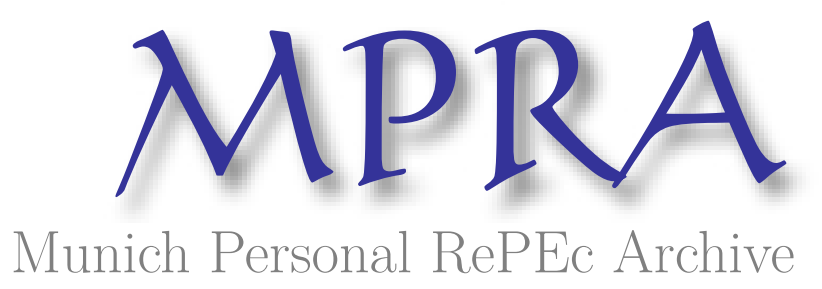

\title{
Central bank independence, policies and reforms: addressing political and economic linkages
}

\author{
Marianne, Ojo \\ North-West University South Africa
}

7 March 2014

Online at https://mpra.ub.uni-muenchen.de/54205/

MPRA Paper No. 54205, posted 07 Mar 2014 19:52 UTC 


\title{
Central Bank Independence, Policies and Reforms: Addressing Political and Economic Linkages
}

\begin{abstract}
Whilst economic, political linkages and relationships constitute the theme of this paper, the paper also attempts to address why central bank independence still lacks certain vital attributes which embody adequate governance and accountability mechanisms - which are necessary if better results in relation to longer term economic and political objectives, in particular, are to be achieved.

From this perspective, the growing importance of the shift to a focus on distinguishing between micro and macro prudential regulation is illustrated. The need for such distinction is not just evidenced through the creation of agencies responsible for such affairs within particular jurisdictions which are considered in this paper, but also through the increased realisation and need for greater focus on decision making responsibilities which are to be assigned to political and economic entities at supra national levels.
\end{abstract}

Financial stability, it appears, has more to do with a mere focus on longer term objectives. Financial stability is also concerned with the ability to sustain long term policy objectives whilst being flexible enough to respond effectively to short term unpredictabilities.

Key Words: inflation targeting, monetary policies, central banks, fiscal policies, accountability, governance arrangements, momentum effects 


\title{
Central Bank Independence, Policies and Reforms: Addressing Political and Economic Linkages
}

\author{
Marianne Ojo
}

\section{A Introduction}

This paper aims to highlight how the focus on the distinctions between central bank monetary policy-setting functions, supervisory and regulatory functions, have been impacted by recent global financial crises. In so doing, it illustrates the shift towards micro prudential and macro prudential policies aimed at fostering financial stability. Within the context of central bank independence, even though the distinctions between monetary policy-setting, regulatory and supervisory functions are frequently emphasized, it is possible for a central bank to operate successfully - even where regulatory and supervisory functions are governed by, or subjected to relatively high degrees of external influences. This is evidenced by the creation of separate regulatory and supervisory agencies which are responsible for supervision and regulatory functions - as distinct from the monetary policy-setting functions that are within the scope and jurisdiction of the central bank. Even though it is also argued that independent monetary policy is, and has been, very pivotal as a deterrent to inflation (Kohn, 2013:104), it is still possible for a central bank to function effectively where it combines monetary policy-setting functions with supervisory and regulatory functions - provided adequate governance mechanisms and institutional arrangements are in operation to ensure that accountability is fostered. It could also be inferred that "independent monetary policy" refers to freedom and independence from political, external influences which could impair monetary policy setting judgments.

"Sustained policy actions", , are indeed necessary if long term stability and growth objectives are to be achieved. The difficulties in a focus on long term objectives which are crucial to the fostering of financial stability and the achievement of other monetary policy objectives such as long periods of low level inflation, can be primarily attributed to difficulties and the degree of inaccuracies associated with forecasting.

The difficulties in accurately predicting and forecasting levels of GDP growth rates, as well as the reliability on economic indicators as measures of growth in GDP, are widely acknowledged - given the presence of several prevailing factors and economic variables which impact on the behaviour, as well as which govern outcomes of the economy. It is a

\footnotetext{
${ }^{1}$ Professor, Faculty of Commerce and Administration, North-West University, South Africa

${ }^{2}$ A Meltzer (2013:99)
} 
well-known fact that quarterly real GDP growth rates are subject to factors which make them relatively unpredictable - as well as variable.

\section{B Explanations For Monetary Policy Focus on Short Term Objectives}

The Fed Reserve and the Bank of England recently acknowledged that whilst the labour market plays a crucial role in adjusting or setting policy, that it was not the only factor to be considered since in their view, "the headline rate of employment does not accurately measure labour-market conditions." In this respect, reference was also made to the fact that figures which showed that unemployment had fallen recently in the U.S did not necessarily mean people were getting jobs but could be partly indicative of the fact that they were quitting or temporarily leaving the work force. The Fed's current chairman, Yellen also indicated that "the Fed is looking beyond traditional measures of unemployment to judge the tightness of the labour market - as well as detect pressure on inflation."

Given the difficulties with forecasting future economic performances, results and outcomes, it is quite understandable why many central banks would wish to focus on short term objectives and targets. However, it is also argued my Meltzer (2013:101) that "excessive attention to short-term changes neglects the distinction between permanent and temporary changes", which, in his view, are considered critical and pivotal to basic and fundamental economic analyses.

In a statistical based regression analysis undertaken by Hawksworth and Teh (2013), such analysis being aimed at investigating the reliability of stock markets in predicting future growth, and such comparative analysis being undertaken between the UK and the US, the following conclusions were derived:

- That changes in UK stock market prices have not provided reliable predictions of short term future GDP growth or changes in the employment rate in the U.K. This result differing from that obtained for the U.S.

In addition to several factors which were identified as being explanatory for these differences in results, another vital and interesting observation was made in relation to the "momentum effect". It was further discovered by Hawksworth and Teh that high momentum effects existed in the U.S economy - whereby "growth in one quarter feeds strongly into growth in the next quarter." In their opinion, the reason for this being that a stock price increase in the U.S triggers short term boost in consumer spending - which they further argue, feeds through to the economy quickly, boosting growth and reducing unemployment.

In contrast, their results derived for the UK, indicated a less pronounced momentum effect. 
Such "momentum effect" can be considered a contributory factor to the Fed Reserve's focus on short term goals and objectives.

Meltzer, however, argues that, in addition to incidences which illustrate the Fed Reserve's tendency to focus on short term objectives (these including a focus on series of actions referred to as QE2 in the summer of 2010), other errors are reflected by its reliance on the Phillips curve (whereby he $\operatorname{argues}^{3}$ that the main weakness of the curve derives from changes in expected inflation and sustained output growth).

The impact of expected inflation is further evidenced and illustrated by Ashton (2012:14) in a reference to a speech delivered by Fed Reserve Chairman, Ben Bernanke in 2007:

- "Undoubtedly, the state of inflation expectations greatly influences actual inflation and thus the central bank's ability to achieve price stability."

Extraordinary times do call for extraordinary measures and responses. As recent financial crises have revealed, across several jurisdictions, the responses taken by central banks in reacting and responding to emergency situations which have the potential to severely impact financial stability, have been determined, not just by prevailing political environments, but also by institutional arrangements which were in place at the time.

\section{Central Bank Reforms, Structures, Political and Economic Linkages: A Global Comparison}

Whilst the Fed Reserve is distinguished from the European Central Bank, in view of the dual mandate assigned to the Fed Reserve, such distinction, according to Schmieding (2012:180), is likely to diminish over the years - given future plans to facilitate the ECB's accountability for labour markets trends, Schmieding also highlights three reasons why the ECB, in his opinion, is the most independent central bank in the world:

- The ECB does not interact with just one finance minister but a group of 17 national finance ministers who frequently have different opinions on a matter

- In the United States, it would take one act of Congress (and in the United Kingdom, one act of Parliament), to amend the mandate or set-up of the central bank. In comparison, in the Eurozone, it is not possible for any politician to threaten, with credibility, implicitly or explicitly change the mandate of the central bank or the process through which board members are selected - if the direction of monetary policy is disagreed with.

\footnotetext{
${ }^{3} \mathrm{He}$ argues that Phillips curves assume that sustained output growth is given - whereas evidence rejects such assumption.
} 
- That the ECB considers itself to be the "heir to best practice monetary policy" in Europe.

It is however important to highlight the fact that whilst the ECB may be endowed with the above features, its inability to execute certain vital decision making functions has been exposed as a result of the ongoing Eurozone Crisis. Ortiz (2012:12) adds that the problem lies within the linkage between the European fiscal crisis and the European political crisis. He argues that "only the ECB has the power and ability to make decisions, but that the mandate and scope of the bank is in the sphere of monetary policy and financial stability."

Such need for accountability, better governance arrangements, coherence and fundamental link between political authorities, financial, fiscal and monetary objectives and authorities, is also partly attributable to the need for the most recent institutional supervisory arrangements which have taken place within the UK's regulatory landscape. Flaws and failures in pre-crisis arrangements prompted regulatory reforms which came into effect in April 2013 in the UK. The reform resulted in the Bank of England acquiring "significant new responsibilities" as follows (Bank of England: 2013):

- Responsibility for micro prudential regulation of insurers, deposit takers and major investment firms - through the creation of the Prudential Regulation Authority

- Responsibility for macro prudential regulation of the financial system as a whole, through the creation of the Financial Policy Committee; and

- Supervision of certain critical post trade financial market infrastructures

These reforms being aimed at fostering the Bank's accountability to Parliament and the public. The distinctions between responsibilities for micro and macro prudential regulation is also evident and these can be regarded as partly attributable to the need to liaise more effectively with overseas authorities, as well as the need for better compliance with EU and global legislation and directives. Creation of the Financial Policy Committee is also evidential of greater recognition and acknowledgement of the importance of risks which could emanate, trigger systemic contagion - hence, de-stabilising the entire financial system.

As part of changes being made to address failing institutions, the Financial Services Act 2012 (the Act), "extends modified versions of the special resolution regime created for banks in 2009 to investment firms and recognised clearing houses." 4

\footnotetext{
${ }^{4}$ Such reforms being aimed at providing the Bank of England and HM Treasury with powers to deal with failing firms of such classification in order to "protect the stability of the financial system" and such powers being expected to be supplemented in significant respects, by the EU's Recovery and Resolution Directive
} 
New Regulatory Framework: Source (Research and Analysis, Changes to the Bank of England, page 21)

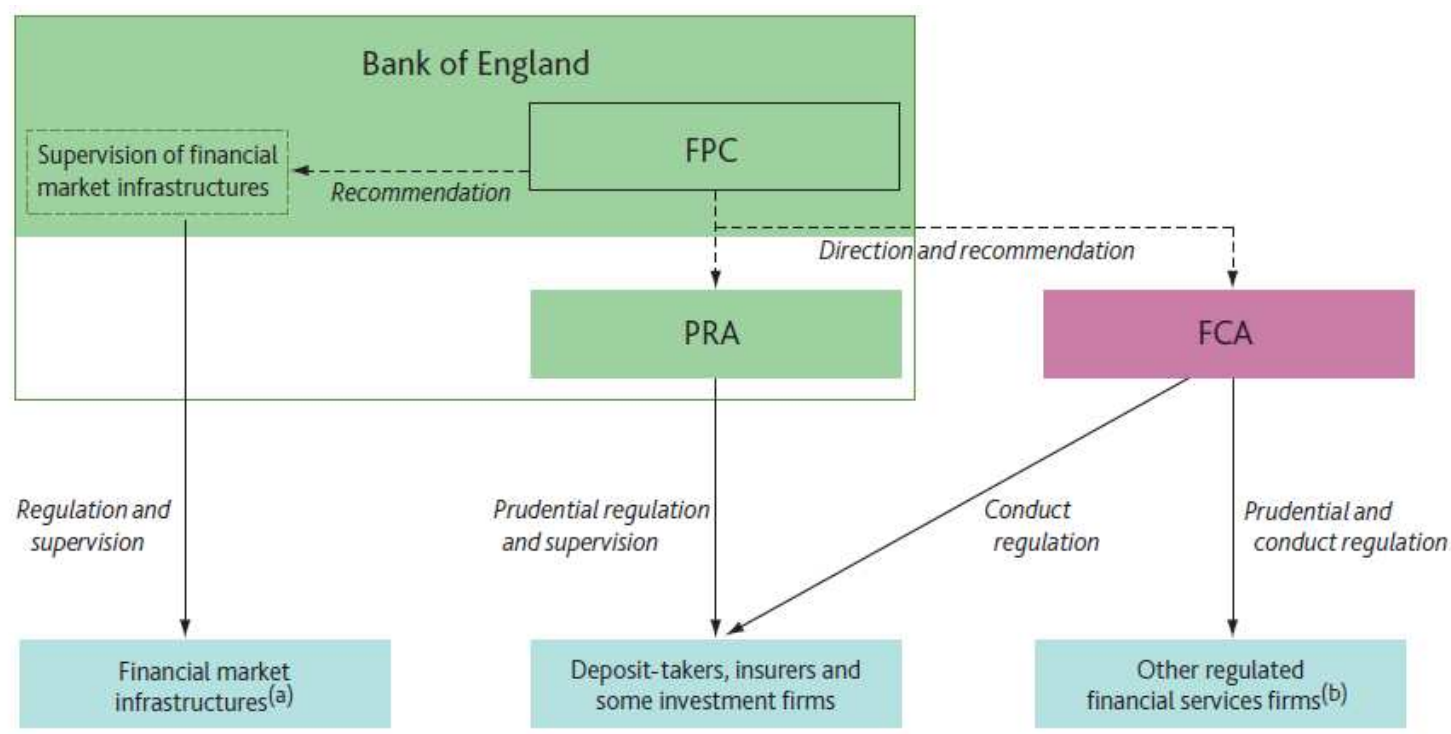

(a) Excludes regulation of trading platforms, which is the responsibility of the FCA.

(b) Includes asset managers, hedge funds, exchanges, insurance brokers and financial advisers. 
Major Decision Making Responsibilities (Statutory) of the Bank of England

Source (Research and Analysis, Changes to the Bank of England, page 21)
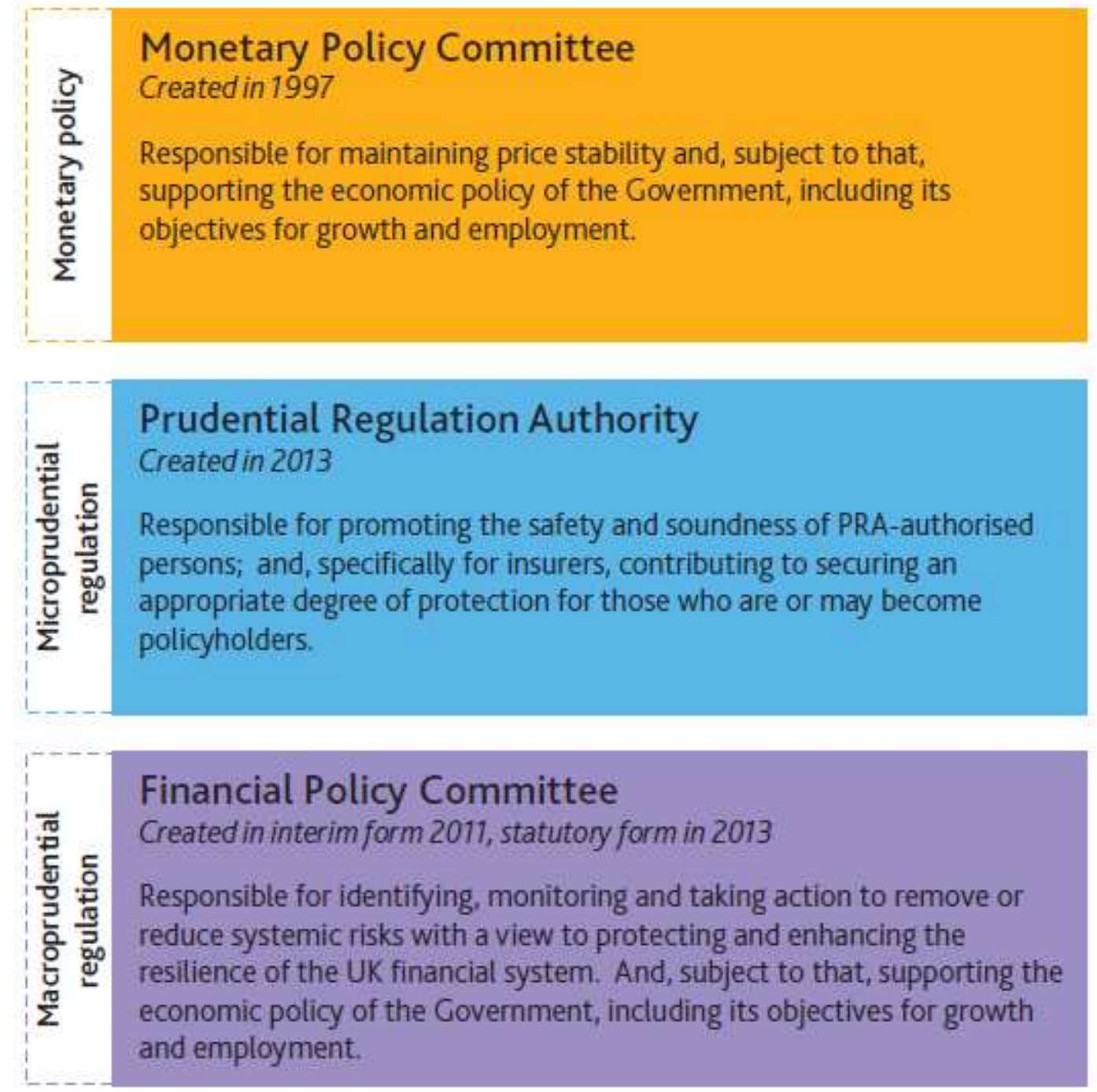

From the above diagrams, it can be illustrated that it is possible for a central bank to operate successfully and effectively even where regulatory and supervisory functions are subjected to external control or influences of other organs. Crucial to such effective functioning is the need for close collaboration, communication and collaboration between financial, supervisory and governmental authorities, organs and bodies involved. In addition to the effective allocation and designation of responsibilities, checks and monitors (investigative reports) are crucial to ensuring that these authorities perform their duties without external pressures or threats to their functions. 


\section{CONCLUSION}

In relation to measures and recommendations aimed at fostering greater central bank independence, Kohn argues that "instrument independence is necessary to overcome the short-term perspective of politicians, who are more interested in boosting growth for future elections and less focussed on the longer-term inflationary consequences of such actions."

The need to adhere to rules and policies - even where there are political and fiscal pressures to break such policies or rules, becomes all the more crucial with monetary unions where greater coordination is required between authorities and member states, and also where greater and far-reaching repercussions exist in the case where rules are not complied with by more influential member states. A decision making authority whose rules are binding - to the effect that even more significant and influential member states are not able to circumvent such rules, is required for in economic and fiscal matters - as well as political decision making issues. Even though (Ortiz 2012:12) is of the opinion that "the question regarding the effectiveness of policymaking - or lack of it - in the Euro area, is concerned with the absence of political mechanisms", there is no doubt that political leadership and mechanisms exists the question and issue relates to the identity which such political leadership will assume and the direction in which such leadership and political mechanisms will operate. Furthermore, clearer, more defined rules and guidelines will be hugely beneficial in facilitating more coordinated economic and political linkages which will foster better outcomes and results in matters particularly related to central bank independence.

As well as providing clearer guidelines in relation to reasons why certain monetary policies are no longer adopted, for example, reasons for giving more scope for consideration of other economic indicators - beyond that of traditional measures of employment, the approach of providing investors with more information, but not linking policy to specific indicators, is greatly welcomed. 


\section{REFERENCES}

Ashton, M. (2012), "Real-Feel Inflation: Quantitative Estimation of Inflation Perceptions" Business Economics Volume 47, No 1, pages 14-26

Bank of England (2013), Research and Analysis : Changes to the Bank of England, Quarterly Bulletin 2013 Q1

http://www.bankofengland.co.uk/publications/Documents/quarterlybulletin/2013/qb130102.p $\underline{\mathrm{df}}$

Bernanke, B.S. (2007). "Inflation Expectations and Inflation Forecasting," At the Monetary Economics Workshop of the National Bureau of Economics Research Summer Institute,Cambridge, MA July 10

http://www.federalreserve.gov/newsevents/speech/bernanke20070710a.htm

Brunner, K. A Cukierman, and A.H. Meltzer (1980), "Stagflation, Persistent Unemployment, and the Permanence of Economic Shocks" Journal of Monetary Economics, October :467-92

Business Report (2014) Fed, BoE Promise Simplicity in the Future

Hawksworth, J. and Teh Y L (2013), “Are Stock Markets Reliable Leading Indicators of the Real Economy For the US and the UK?" PricewaterhouseCoopers Publications

Kohn, D. (2013) "Federal Reserve Independence in the Aftermath of the Financial Crisis: Should WE Be Worried? ?” Business Economics Volume 48, No 2,pages 104 - 107

Meltzer, A. (2013) "What's Wrong With the Federal Reserve: What Would Restore Independence?" Business Economics Volume 48, No 2,pages 96-103

Ortiz, G. (2012) "What Can the Developed World Learn From the Latin American Debt and Mexican Peso Crisis?” Business Economics Volume 47, No 1, pages 2-13

Schmieding, H. (2012) "Tough Love: The True Nature of the Eurozone Crisis" Business Economics Volume 47, No 3 pages 177-189 